\title{
Post percutaneous coronary intervention hemoglobin levels predict in-hospital mortality in patients with STEMI treated with primary percutaneous coronary intervention
}

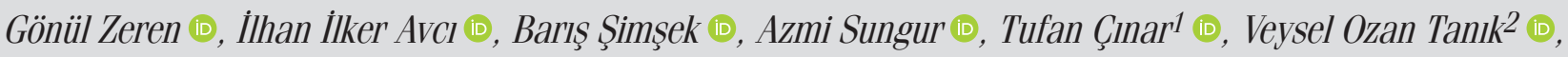 \\ Duygu Genç (i), Göksel Çinier (i), Can Yücel Karabay (i)
}

Department of Cardiology, Dr. Siyami Ersek Thoracic and Cardiovascular Surgery Training and Research Hospital; İstanbul-Turkey

${ }^{1}$ Department of Cardiology, Sultan Abdulhamid Han Training and Research Hospital; İstanbul-Turkey

2Department of Cardiology, Ankara Dışkapı Yıldııım Beyazıt Training and Research Hospital; İstanbul-Turkey

\section{ABSTRACT}

Objective: In this study, we aimed to determine whether admission hemoglobin versus post-percutaneous coronary intervention (PCI) hemoglobin level at 24 hours is a predictor of in-hospital mortality for patients with ST elevation myocardial infarction (STEMI) without evidence of clinical hemorrhage who underwent primary PCI.

Methods: In this study, we included 1,444 consecutive patients with STEMI who underwent primary PCI at a tertiary heart hospital. The primary outcome of the study was the in-hospital all-cause mortality. We used the penalized maximum likelihood estimation (PMLE) logistic regression method to examine the relationship between primary outcome and candidate predictors.

Results: In total, $172(11.9 \%)$ patients died during the in-hospital course. According to a PMLE logistic regression analysis, age, KILLIP class $\geq 2$, pre-PCI thrombolysis in myocardial infarction (TIMI) flow $<3$, systolic blood pressure, creatinine, glycoprotein IIb/IIla inhibitor use, and post-PCI hemoglobin levels at 24 hours were predictors of in-hospital mortality. The relative importance of post-PCl hemoglobin at 24 hours (contributing $6 \%$ of the explainable outcome in the model) was significantly higher than admission hemoglobin (contributing only $0.1 \%$ of the explainable outcome in the model).

Conclusion: This study demonstrated that post-PCI hemoglobin levels were independently associated with in-hospital survival in patients with STEMI without evidence of bleeding following primary PCI. In addition, post-PCI hemoglobin was a better predictor of in-hospital mortality than admission hemoglobin for patients with STEMI who underwent primary PCI.

Keywords: post-percutaneous coronary intervention hemoglobin, admission hemoglobin, ST-segment elevation myocardial infarction, primary percutaneous coronary intervention, in-hospital mortality

Cite this article as: Zeren G, Avcı II, Şimşek B, Sungur A, Çınar T, Tanık VO, et al. Post percutaneous coronary intervention hemoglobin levels predict in-hospital mortality in patients with STEMI treated with primary percutaneous coronary intervention. Anatol J Cardiol 2021; 25: 623-9.

\section{Introduction}

In the current literature, the majority of previous studies have been mainly focused on admission hemoglobin levels in patients who present with acute coronary syndrome (ACS). Although some studies found that admission hemoglobin level is associated with increased in-hospital and long-term mortality in patients diagnosed with ST elevation myocardial infarction (STEMI) $(1,2)$, others have found no significant association $(3,4)$. Similarly, there is an inconsistent relation of admission hemoglo- bin level and poor cardiovascular outcomes in patients with STEMI who are treated with primary percutaneous coronary intervention (PCI) $(5,6)$. Apart from admission hemoglobin level, prior studies have revealed that hemoglobin drop following primary $\mathrm{PCl}$ might be related with adverse cardiovascular outcomes and mortality among patients with STEMI $(7,8)$. In such clinical circumstances, hemoglobin drop usually represents clinically significant hemorrhage, including retroperitoneal, gastrointestinal, or intracranial hemorrhage, all of which usually occur owing to anti-platelet or anti-thrombotic treatment or the

Address for Correspondence: Dr. Gönül Zeren, Dr. Siyami Ersek Eğitim ve Araştırma Hastanesi, Kardiyoloji Kliniği, İstanbul-Türkiye

Phone: +90 5055837690 E-mail: gonulzeren@hotmail.com

Accepted Date: 23.03.2021 Available Online Date: 17.08.2021

(C) Copyright 2021 by Turkish Society of Cardiology - Available online at www.anatoljcardiol.com DOI:10.5152/AnatolJCardiol.2021.07282 


\section{HIGHLIGHTS}

- Post-percutaneous coronary intervention (PCI) hemoglobin levels are independently associated with inhospital survival in patients with ST-segment elevation.

- Post-PCI hemoglobin is a better predictor of in-hospital mortality than admission hemoglobin in these patients.

- The other mortality predictors in patients with STEMI are age, KILLIP class $\geq 2$, pre- $\mathrm{PCI}$ thrombolysis in myocardial infarction flow $<3$, systolic blood pressure, creatinine, and glycoprotein Ilb/IIla inhibitor use.

procedure itself. However, a decline of hemoglobin without an evidence of hemorrhage after primary $\mathrm{PCI}$ may be because of internal hemodilution, an acute inhibition of erythropoiesis, elevated inflammation, or catheter flushing and leakage (9-11). Particularly, a decline of hemoglobin after primary PCl may have the potential to increase myocardial ischemic injury by preventing the oxygen supply to the jeopardized myocardium (12). Although the results of hemoglobin drop in patients with STEMI with bleeding are well-known, there is limited data regarding the effect of hemoglobin drop on in-hospital mortality in these patients with no evidence of bleeding and treated with primary $\mathrm{PCI}$. Therefore, in this study, we aimed to determine whether admission hemoglobin versus post-PCI hemoglobin level at 24 hours was a predictor of in-hospital mortality in patients with STEMI without evidence of clinical hemorrhage who underwent primary PCl.

\section{Methods}

\section{Data collection}

This study included 1,444 consecutive patients with STEMI who underwent primary $\mathrm{PCl}$ at a tertiary heart hospital. Our hospital was a high volume heart center with the capability of performing $>1,000$ primary PCls annually. In this study, patients who were treated with thrombolytic therapy, had admission hemoglobin levels $<10 \mathrm{mg} / \mathrm{dL}$, had received blood transfusion (s), and developed retroperitoneal, gastrointestinal, or intracranial hemorrhage following primary $\mathrm{PCI}$ were excluded from the study. In addition, we did not include patients who developed groin complications and whose hemoglobin levels were not measured at 24 hours after primary PCl. All the patients enrolled in the study were treated according to the current guidelines. In the study, we evaluated each patient according to KILLIP class examination findings at admission. Demographic features, including age, sex, and risk factors, as well as laboratory and angiographic findings were collected from the hospital electronic database. The study was approved by the Local Ethics Committee and performed according to the Declaration of Helsinki of 1975, as revised in 2008. Informed consent was not obtained because of the retrospective design of the study.

\section{Coronary angiography and percutaneous coronary intervention}

Standard coronary angiography via the femoral route was performed in each patient using 6-French Judkins diagnostic catheters. In all the patients, $300 \mathrm{mg}$ acetylsalicylic acid along with a loading dose of either $600 \mathrm{mg}$ of clopidogrel or $180 \mathrm{mg}$ of ticagrelor or $60 \mathrm{mg}$ of prasugrel were given before the coronary angiography unless contraindicated. The standard intravenous bolus of unfractionated heparin (UF) $(70-100 \mathrm{U} / \mathrm{kg}$ ) with additional doses if necessary, was given to achieve an activated clotting time of $>250$ seconds during $\mathrm{PCl}$. Per institutional proto$\mathrm{col}$, the use of glycoprotein Ilb/Illa inhibitor was left to the operator's judgment. Two experienced cardiologists, who were blinded to all the clinical data, analyzed the thrombolysis in myocardial infarction (TIMI) flow grade before the intervention. In cases of disagreement, the cardiologists reviewed the coronary angiograms and came to a joint agreement. The SYNTAX scoring system was used to evaluate the severity of coronary artery disease using an online web calculator (http://www.syntaxscore.com/calculator/start).

\section{Laboratory analysis}

Blood samples, including hemoglobin, creatinine, and lipid profiles, were measured in all the patients following admission to hospital. A hematology analyzer (Beckman Coulter, FL, USA) was used for complete blood count analysis of the samples, and Beckman Coulter LH 780 device (Beckman Coulter Ireland Inc., Mervue, Galway, Ireland) was used to analyze the standard biochemical parameters.

\section{Primary outcome}

The primary outcome of the study was the in-hospital allcause mortality. A trained study coordinator evaluated all electronic medical records and confirmed in-hospital mortality.

\section{Definitions}

STEMI is described as proposed in the recent universal definition of myocardial infarction guidelines (13). Major bleeding was described in accordance of the definition proposed by the Bleeding Academic Research Consortium categories (14). All major bleeding events were evaluated by an experienced cardiologist by examining the patients' medical records. Major adverse cardiac events (MACEs) were defined as the combination of cardiac mortality, advanced atrioventricular block, and malignant ventricular arrhythmias.

\section{Statistical analysis}

For statistical analysis, 'rms' and 'Hmisc' packages with R-software v. 3.5.1 (R Statistical Software, Institute for Statistics and Mathematics, Vienna, Austria) was used. Categorical variables were presented as numbers and percentages, and continuous variables were presented as median and interquartile range (IO). We used the Mann-Whitney $\mathrm{U}$ test for between group comparison to compare continuous variables, and the chisquared test for between group comparison to compare categorical variables. 


\begin{tabular}{|c|c|c|}
\hline & $P$-value & OR (95\% CI) \\
\hline Male sex & 0.84 & $1.04(0.66-1.65)$ \\
\hline Age & 0.007 & $1.26(0.94-1.68)$ \\
\hline KILLIP class $\geq 2$ & $<0.001$ & $11.0(6.7-18.1)$ \\
\hline Pre-PCI TIMI flow <3 & $<0.001$ & $0.26(0.17-0.40)$ \\
\hline Systolic blood pressure & $<0.001$ & $0.59(0.45-0.77)$ \\
\hline Heart rate & 0.309 & $1.21(0.94-1.54)$ \\
\hline Creatinine & 0.002 & $1.10(0.97-1.25)$ \\
\hline Admission hemoglobin & 0.958 & $0.96(0.62-1.48)$ \\
\hline Post-PCl hemoglobin at $24 \mathrm{~h}$ & 0.049 & $0.56(0.34-0.93)$ \\
\hline Glycoprotein Ilb/IIla inhibitor use & 0.034 & $1.59(1.03-2.44)$ \\
\hline MI type, non-anterior & 0.260 & $1.25(0.84-1.87)$ \\
\hline
\end{tabular}

$\mathrm{OR}$ - odds ratio; $\mathrm{Cl}$ - confidence interval; $\mathrm{PCl}$ - percutaneous coronary intervention; TIMI - thrombolysis in myocardial infarction

Primary outcome: In-hospital mortality was the primary outcome in the study.

Candidate predictors: It is important that the candidate predictors included in the model are clinically and biologically plausible and that their association with in-hospital mortality has been demonstrated. Variables with very low or very high frequency were not included in the model. We used the penalized maximum likelihood estimation (PMLE) logistic regression method to examine the relationship between primary outcome and candidate predictors (Table 1). The candidate predictors included in the model were age, sex, Ml type, systolic blood pressure, heart rate, creatinine, KILLIP class, TIMI flow, glycoprotein $\mathrm{Ilb} / \mathrm{Illa}$ inhibitor use, admission hemoglobin, and post$\mathrm{PCI}$ hemoglobin at 24 hours. Odds ratio (OR) and a 95\% confidence interval (Cl) were used to demonstrate the effects of individual predictors on in-hospital mortality. In the model, the relative importance of each predictor was determined with partial $X^{2}$ value for each predictor divided by the model's total $X^{2}$, which represents the independent contribution of the predictor to the variance of the outcome. A $p$ value $<0.05$ was considered statistically significant.

\section{Results}

This was the clinical data of 1,444 consecutive patients with STEMI, of which $302(20.9 \%)$ were women. In total, $172(11.9 \%)$ patients died during the in-hospital course. The study cohort was divided into two groups; survivors and non-survivors.

Baseline demographic features, laboratory findings, and interventional outcomes of all the patients are summarized in Table 2. Patients in the non-survivor group were older and female. Hypertension, diabetes, hyperlipidemia, active smoking, prior myocardial infarction (MI) and cerebrovascular accident (CVA), chronic heart failure, and chronic renal failure were more frequent in patients who died during in-hospital stay than in those who survived ( $p<0.05$, for each). In terms of laboratory analysis, patients in the non-survivor group had significantly higher admission glucose, creatinine, and white blood cell count; whereas their admission hemoglobin and post-PCI hemoglobin at 24 hours were significantly lower ( $p<0.05$, for each). The other laboratory results were fairly similar between the groups. On admission, patients who did not survive during inhospital course had significantly lower systolic and diastolic blood pressures in addition to having higher heart rate and KILLIP class examination findings ( $p<0.05$, for each). Comparison of angiographic findings revealed that non-anterior $\mathrm{MI}$ and preTIMI flow $<3$ were more frequent in the non-survivor group $(p<0.05$, for each). When we analyzed the study cohort in terms of in-hospital adverse outcomes, the frequency of in-hospital malignant arrhythmia and CVA were more common in the nonsurvivor group than in the survivor group [28 $(17 \%)$ patients vs. 0 $(0 \%)$ and $13(8 \%)$ patients vs. 0 cases $(0 \%)$, respectively].

To determine predictors of in-hospital mortality, we performed the PMLE logistic regression analysis. According to this analysis, age, KILLIP class $\geq 2$, pre-PCI TIMI flow $<3$, systolic blood pressure, creatinine, glycoprotein Ilb/llla inhibitor use, and post- $\mathrm{PCI}$ hemoglobin levels at 24 hours (OR: $0.56,95 \% \mathrm{Cl}: 0.34-0.93, p=0.049$ ) were predictors of in-hospital mortality. The model's goodness of fit was measured by the likelihood ratio (LR) test (LR=438.99), discrimination index $\left(R^{2}=0.493\right)$, and rank discrimination index (c-index $=0.901$ ). Figure 1 presents the relative importance of each predictor in the model. The relative importance of post- $\mathrm{PCl}$ hemoglobin at 24 hours (contributing $6 \%$ of the explainable outcome in the model) was significantly higher than admission hemoglobin (contributing only $0.1 \%$ of the explainable outcome in the model). Figure 2 shows that the probability of in-hospital death is significantly elevated as the hemoglobin drop after primary $\mathrm{PCI}$ was higher at 24 hours. We also performed a subanalysis between

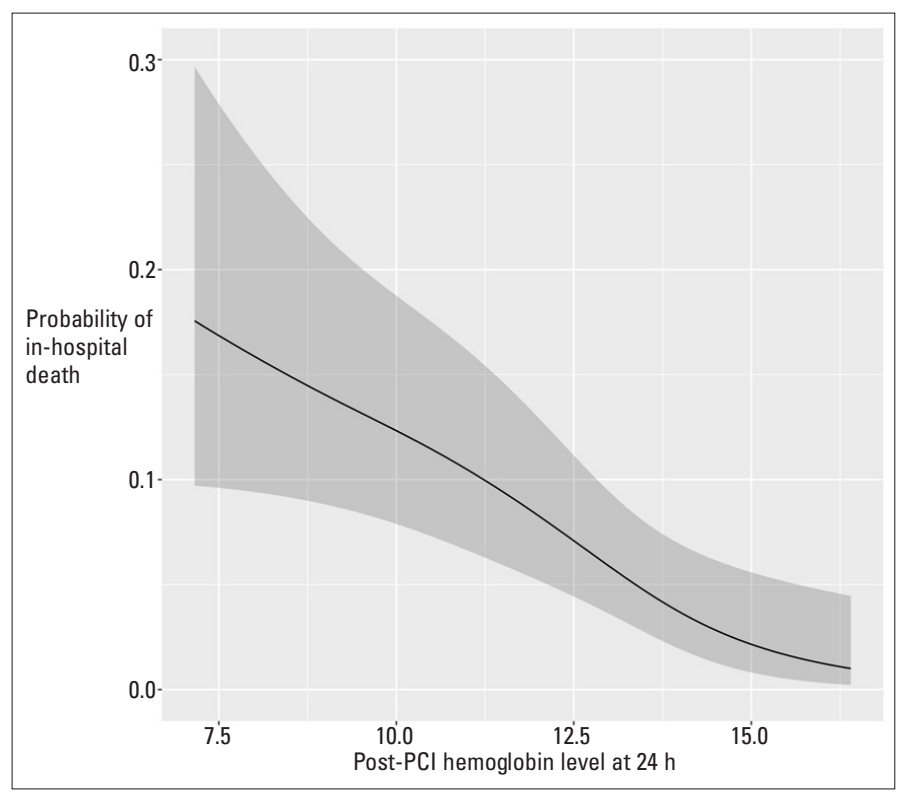

Figure 1. The probability of in-hospital mortality according to postpercutaneous coronary intervention hemoglobin level at 24 hours 


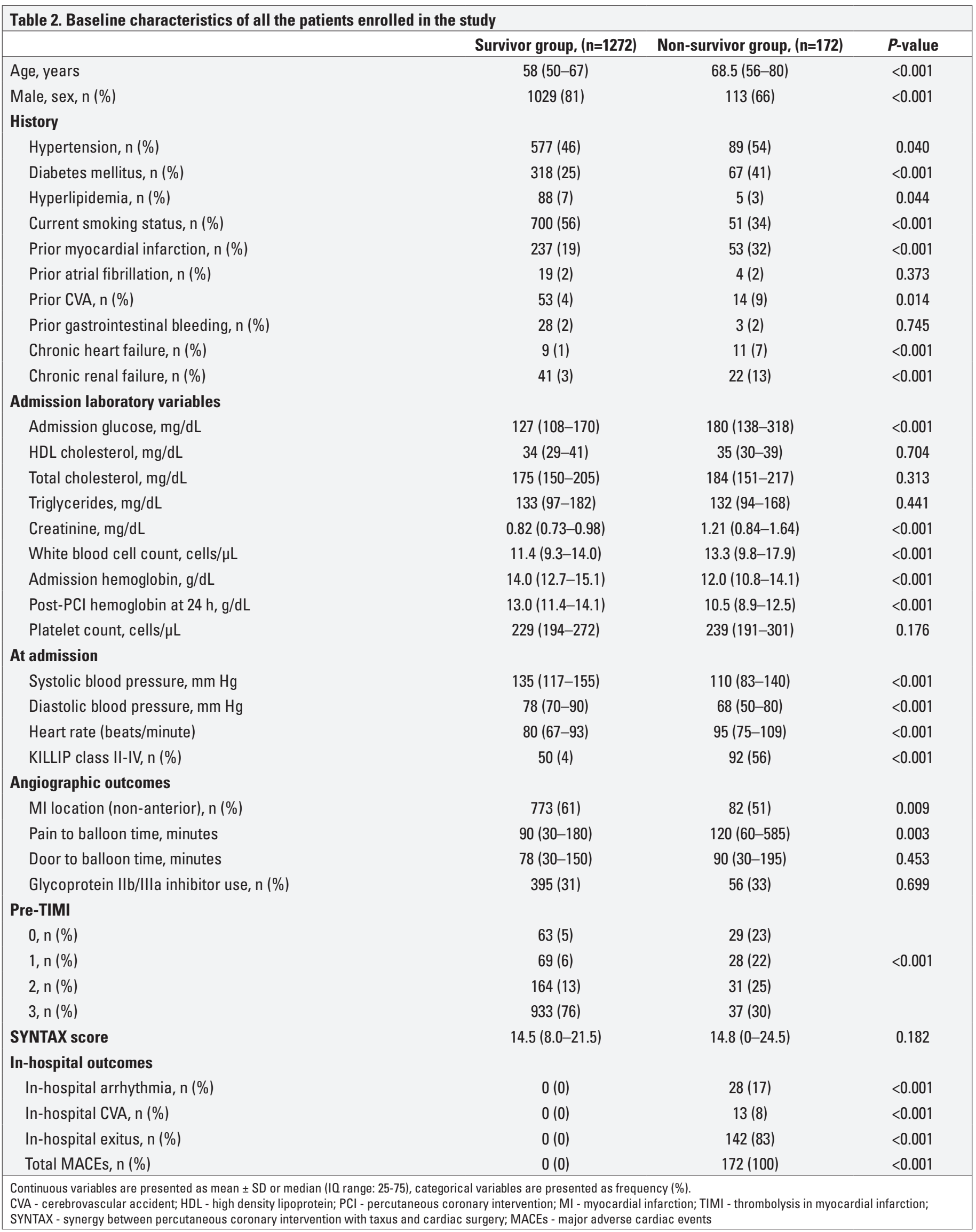




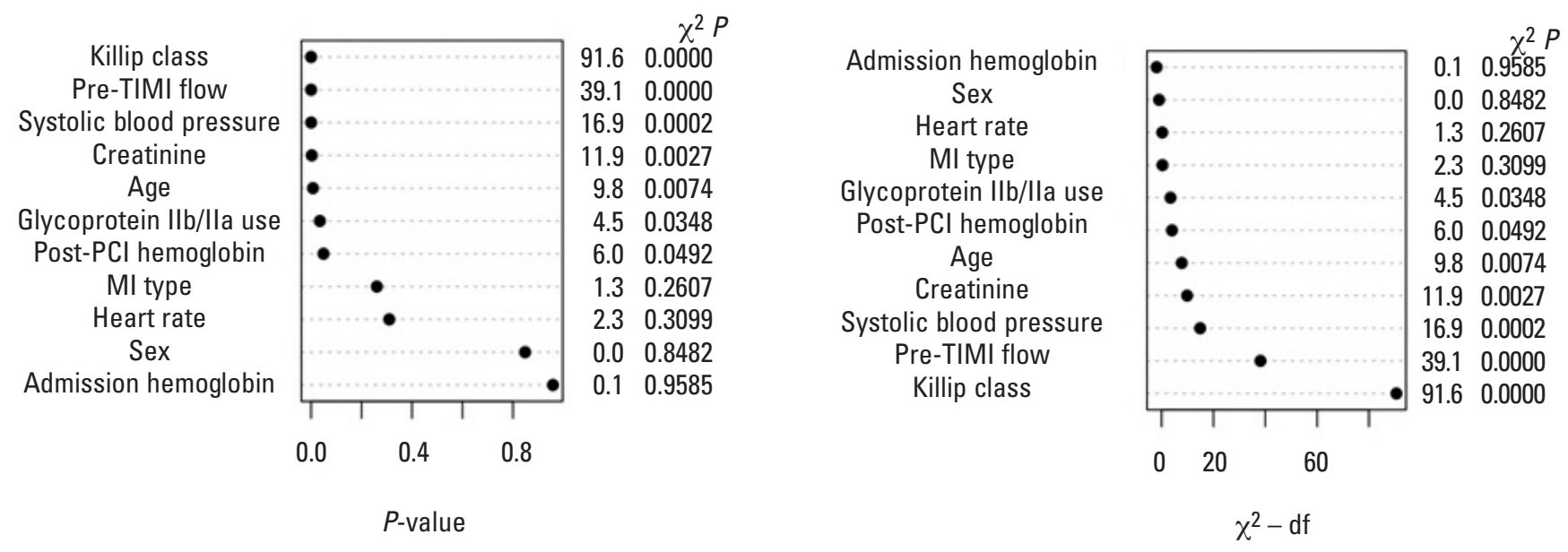

Figure 2. The relative importance of each predictor in the model

post- $\mathrm{PCl}$ hemoglobin and age, female sex, glycoprotein IIb/Illa inhibitor use, creatinine, pre-PCI TIMI flow, KILLIP class $\geq 2$, systolic blood pressure, heart rate, and $\mathrm{MI}$ type. There was no correlation between post- $\mathrm{PCl}$ hemoglobin and age $(\mathrm{p}=0.799)$, female sex ( $p=0.492)$, glycoprotein Ilb/llla inhibitor use $(p=0.067)$, pre-PCI TIMI flow ( $p=0.962$ ), KILLIP class $\geq 2$ ( $p=0.188$ ), systolic blood pressure $(p=0.549)$, heart rate $(p=0.168)$, $M I$ type $(p=0.413)$, except creatinine ( $p=0.045)$ (Fig. 3).

\section{Discussion}

This study demonstrated that post-PCl hemoglobin levels at 24 hours may be a predictor of in-hospital mortality among patients with STEMI who underwent primary PCI.

According to previous studies, anemia is a common clinical finding in patients hospitalized with STEMI, and its prevalence ranges from $10 \%$ to as high as $43 \%$ (15). During the process of acute STEMI, anemia may aggravate acute myocardial injury via decreasing oxygen supply and content to the endangered myocardium and via increasing cardiac output to maintain an adequate systemic circulation (12). Currently, most studies have investigated the predictive value of admission hemoglobin levels for in-hospital mortality of patients with STEMI who underwent primary PCl. Although some studies have found a significant correlation between admission hemoglobin and in-hospital mortality of patients with STEMI treated with primary $\mathrm{PCI}(4,5)$, a recent study conducted by Moghaddam et al. (6) has shown that baseline hemoglobin levels after controlling of all the possible confounders, such as age, sex, KILLIP class, and so forth, is not associated with increased in-hospital mortality for patients with STEMI following primary PCI. Similarly, we found no significant association between admission hemoglobin and in-hospital mortality in such patients. In the view of the observed lack of correlation between baseline hemoglobin levels and in-hospital death, we considered that admission hemoglobin may not significantly contribute to such mortality risk itself.
Even though it had been demonstrated that approximately one out of four ACS patients had a decline of hemoglobin of at least $2.4 \mathrm{~g} / \mathrm{dL}$ during in-hospital course, major and minor bleeding occurred only in $2.1 \%$ and $7.4 \%$ of such patients, respectively (16). Similarly, clinically significant bleeding was observed in only half of the patients with ACS with a hemoglobin drop of 3 to $4 \mathrm{~g} / \mathrm{dL}$ (16). Therefore, it has been considered that a decline in hemoglobin level and the development of post- $\mathrm{PCl}$ related anemia are caused by different mechanisms other than blood loss. For example, hemodilution induced by intravenous fluids or nitrates may play a role in the development of hemoglobin drop following primary PCI for STEMI (8). Furthermore, the use of angiotensinogen converting enzyme inhibitor and inflammation might inhibit erythropoiesis in the acute phase of STEMI $(9,11)$. Blood loss owing to diagnostic phlebotomy or procedural technique, such as catheter leakage or flushing, may also contribute to hemoglobin decline after primary $\mathrm{PCI}(10)$.

Currently, a few clinical studies have examined the hemoglobin drop and its relation with in-hospital mortality in patients with ACS. In a prospective, multi-center study, Redfors et al. (7) have studied the association between $\Delta \mathrm{Hgb}$ (defined as the magnitude of hemoglobin reduction from baseline during inhospital stay) and in-hospital adverse outcomes in patients with ACS after PCI. They concluded that patients with an $\Delta \mathrm{Hgb} \geq 4 \mathrm{~g} /$ $\mathrm{dL}$ had higher mortality and MACEs, such as stent thrombosis, cardiac death, and myocardial infarction. Moreover, Nabais et al. (16) have reported that the drop in hemoglobin usually occurs during hospitalization for ACS and is an independent predictor of mortality among such patients. However, patients with clinically significant bleeding event(s) in addition to having blood transfusion(s) were not excluded from these studies. The study population was not homogeneous (including patients with nonSTEMI, STEMI, and unstable angina pectoris) in the abovementioned studies. In our study, we found that hemoglobin decline was common in patients with STEMI without evidence of bleeding following primary $\mathrm{PCl}$, and post-PCl hemoglobin level was 


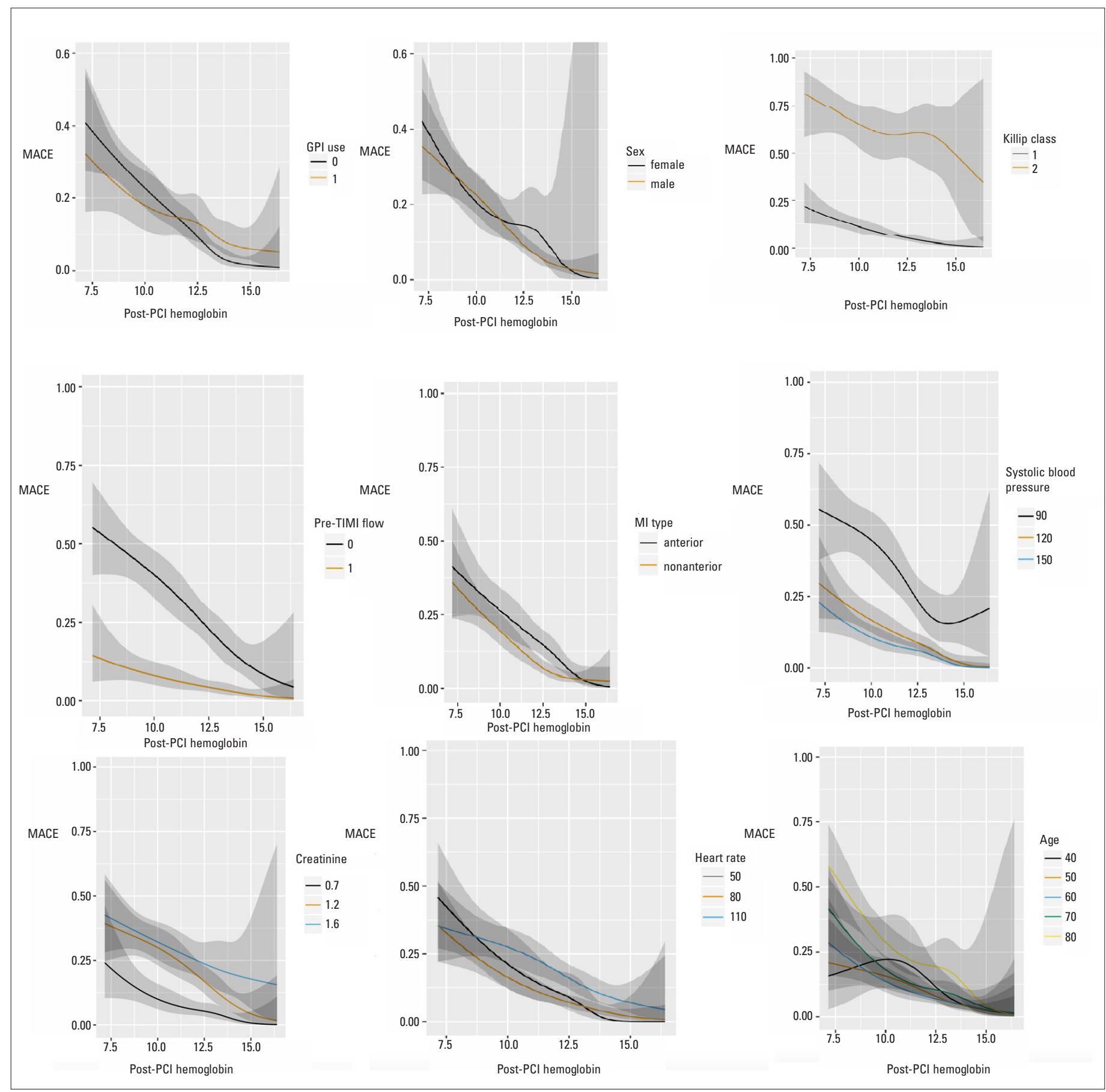

Figure 3. The interaction between post-percutaneous coronary intervention (PCI) hemoglobin and age, female sex, glycoprotein Ilb/IIla inhibitor use, pre-PCI TIMI flow, KILLIP class $\geq 2$, systolic blood pressure, heart rate, myocardial infarction type, and creatinine

independently associated with higher mortality in such patients after the adjustment of clinically important confounders. In addition, we observed no significant association between post-PCI hemoglobin and the predictors of an increased decline in hemoglobin level, including age, female sex, glycoprotein IIb/IIla inhibitor use, and KILLIP class $\geq 2$.

In terms of clinical perspective, our study demonstrates the potential importance of post- $\mathrm{PCI}$ hemoglobin after primary PCI for patients with STEMI without overt bleeding. Because there was a significant correlation between post-PCI hemoglobin and renal dysfunction, particular attention should be paid in such patients. The use of glycoprotein IIb/Illa inhibitor according to baseline renal function, optimal dosing of UF or low molecular weight heparin as well as the use of gastro-protective drugs are the possible options for such patients. A radial vascular route should be the primary choice instead of the femoral vascular route to decrease blood loss following primary PCI (17). 


\section{Study limitations}

This study had a few limitations. The retrospective design of the study was a major limitation. However, all the consecutive patients with STEMI were included in the study. In spite of using multivariate logistic regression analysis, we acknowledge that there might be the possibility of unmeasured confounders, which could affect the results of the study. Because our study was conducted in one geographic region, geographically diverse cohorts are necessary to confirm our findings. Because of the retrospective design of the study, we might have missed some occult bleeding events, all of which might have contributed to a significant hemoglobin decline in some patients. Finally, large prospective cohort studies are needed to determine the exact relation between post- $\mathrm{PCI}$ hemoglobin level and in-hospital survival in patients with STEMI who are treated with primary PCI.

\section{Conclusion}

We demonstrated that post-PCI hemoglobin levels were independently associated with in-hospital survival in patients with STEMI without evidence of bleeding following primary PCI. In addition, post-PCl hemoglobin was a better predictor of inhospital mortality than admission hemoglobin in patients with STEMI who underwent primary $\mathrm{PCI}$.

\section{Conflict of interest: None declared.}

Peer-review: Externally peer-reviewed.

Author contributions: Concept - G.Z., I.I.A., B.S., A.S., T.Ç., V.O.T., D.G., G.Ç., C.Y.K.; Design - G.Z., I.I.A., B.Ş., A.S., T.Ç., V.O.T., D.G., G.Ç., C.Y.K.; Supervision - G.Z., I.I.A., B.S.., A.S., T.Ç., V.O.T., D.G., G.C.., C.Y.K.; Fundings - G.Z., I.I.A., B.Ş., A.S., T.Ç., V.O.T., D.G., G.C.., C.Y.K.; Materials - G.Z., I.I.A., B.Ş., A.S., T.C.., V.O.T., D.G., G.C.., C.Y.K.; Data collection \&/or processing - G.Z., I.I.A., B.Ş., A.S., T.Ç., V.O.T., D.G., G.Ç., C.Y.K.; Analysis \&/or interpretation - G.Z., I.I.A., B.Ş., A.S., T.Ç., V.O.T., D.G., G.Ç., C.Y.K.; Literature search - G.Z., I.I.A., B.Ş., A.S., T.Ç., V.O.T., D.G., G.Ç., C.Y.K.; Writing - G.Z., I.I.A., B.S., A.S., T.C., V.O.T., D.G., G.C.., C.Y.K.; Critical review - G.Z., I.I.A., B.Ş., A.S., T.Ç., V.O.T., D.G., G.Ç., C.Y.K.

\section{References}

1. Tsujita K, Nikolsky E, Lansky AJ, Dangas G, Fahy M, Brodie BR, et al. Impact of anemia on clinical outcomes of patients with ST-segment elevation myocardial infarction in relation to gender and adjunctive antithrombotic therapy (from the HORIZONS-AMI trial). Am J Cardiol 2010; 105: 1385-94. [Crossref]

2. Nikolsky E, Aymong ED, Halkin A, Grines CL, Cox DA, Garcia E, et al. Impact of anemia in patients with acute myocardial infarction undergoing primary percutaneous coronary intervention: analysis from the Controlled Abciximab and Device Investigation to Lower Late Angioplasty Complications (CADILLAC) Trial. J Am Coll Cardiol 2004; 44: 547-53. [Crossref]

3. Al Falluji N, Lawrence-Nelson J, Kostis JB, Lacy CR, Ranjan R, Wilson AC; Myocardial Infarction Data Acquisition system (MIDAS \#8) Study Group. Effect of anemia on 1-year mortality in patients with acute myocardial infarction. Am Heart J 2002; 144: 636-41. [Crossref]

4. Rathod KS, Jones DA, Rathod VS, Bromage D, Guttmann 0, Gallagher SM, et al. Prognostic impact of anaemia on patients with ST-elevation myocardial infarction treated by primary PCI. Coron Artery Dis 2014; 25: 52-9. [Crossref]

5. Dündar C, Oduncu V, Erkol A, Tanalp AC, Sırma D, Karagöz A, et al. In-hospital prognostic value of hemoglobin levels on admission in patients with acute ST segment elevation myocardial infarction undergoing primary angioplasty. Clin Res Cardiol 2012; 101: 37-44. [Crossref]

6. Moghaddam N, Wong GC, Cairns JA, Goodman SG, Perry-Arnesen $\mathrm{M}$, Tocher W, et al. Association of Anemia With Outcomes Among ST-Segment-Elevation Myocardial Infarction Patients Receiving Primary Percutaneous Coronary Intervention. Circ Cardiovasc Interv 2018; 11: e007175. [Crossref]

7. Redfors B, Généreux P, Witzenbichler B, Kirtane AJ, McAndrew T, Weisz G, et al. Bleeding Severity After Percutaneous Coronary Intervention. Circ Cardiovasc Interv 2018; 11: e005542. [Crossref]

8. Previsdomini M, Stocker R, Corti R, Cerutti B, Perren A. Time course of hemoglobin concentrations in the intensive care unit in nonbleeding patients with acute coronary syndrome. Am J Cardiol 2007; 100: 579-82. [Crossref]

9. van der Meer P, Lipsic E, Westenbrink BD, van de Wal RM, Schoemaker $R G$, Vellenga $E$, et al. Levels of hematopoiesis inhibitor N-acetyl-serylaspartyl-lysyl-proline partially explain the occurrence of anemia in heart failure. Circulation 2005; 112: 1743-7. [Crossref]

10. Thavendiranathan P, Bagai A, Ebidia A, Detsky AS, Choudhry NK. Do blood tests cause anemia in hospitalized patients? The effect of diagnostic phlebotomy on hemoglobin and hematocrit levels. J Gen Intern Med 2005; 20: 520-4. [Crossref]

11. Lee WC, Fang $\mathrm{HY}$, Chen $\mathrm{HC}$, Chen $\mathrm{CJ}$, Yang $\mathrm{CH}$, Hang $\mathrm{CL}$, et al. Anemia: A significant cardiovascular mortality risk after ST-segment elevation myocardial infarction complicated by the comorbidities of hypertension and kidney disease. PLoS One 2017; 12: e0180165. [Crossref]

12. Bassand JP. Impact of anaemia, bleeding, and transfusions in acute coronary syndromes: a shift in the paradigm. Eur Heart $\mathrm{J}$ 2007; 28: 1273-4. [Crossref]

13. Thygesen K, Alpert JS, Jaffe AS, Chaitman BR, Bax JJ, Morrow DA, et al.; ESC Scientific Document Group. Fourth universal definition of myocardial infarction (2018). Eur Heart J 2019; 40: 237-69. [Crossref]

14. Mehran R, Rao SV, Bhatt DL, Gibson CM, Caixeta A, Eikelboom J, et al. Standardized bleeding definitions for cardiovascular clinical trials: a consensus report from the Bleeding Academic Research Consortium. Circulation 2011; 123: 2736-47. [Crossref]

15. Stucchi M, Cantoni S, Piccinelli E, Savonitto S, Morici N. Anemia and acute coronary syndrome: current perspectives. Vasc Health Risk Manag 2018; 14: 109-18. [Crossref]

16. Nabais S, Gaspar A, Costa J, Azevedo P, Rocha S, Torres M, et al. Prognostic impact of hemoglobin drop during hospital stay in patients with acute coronary syndromes. Rev Port Cardiol 2009; 28: 383-95.

17. Aktürk E, Kurtoğlu $E$, Ermiş N, Açıkgöz N, Yağmur J, Altuntaş $M S$, et al. Comparision of pain levels of transradial versus transfemoral coronary catheterization: a prospective and randomized study. Anatol J Cardiol 2014; 14: 140-6. [Crossref] 